Int. J. Electrochem. Sci., 11 (2016) $9041-9056$

International Journal of

ELECTROCHEMICAL

SCIENCE

www.electrochemsci.org

\title{
Structural and Electrical Properties of PVA/PVP Blend Doped with Methylene Blue Dye
}

\author{
H. M. Zidan ${ }^{1}$, N. A. El-Ghamaz ${ }^{1}$, A. M. Abdelghany ${ }^{2}$, A. Lotfy, ${ }^{3, *}$ \\ ${ }^{1}$ Physics Department, Faculty of Science, Damietta University. P.O.Box 34517, New Damietta, Egypt. \\ ${ }^{2}$ Spectroscopy Department, Physics Division, National Research Center, 33 ElBehouth St., Dokki, \\ 12311, Cairo, Egypt. \\ ${ }^{3}$ Department of Basic Science, Higher Institute of Engineering and Technology, New Damietta, Egypt. \\ E-mail: ahmedwaves20@yahoo.com
}

doi: $10.20964 / 2016.11 .08$

Received: 19 July 2016 / Accepted: 6 September 2016 / Published: 10 Octobeer 2016

Films of PVA/PVP blend (1:1) doped with different levels of methylene blue dye (MB) were prepared using the casting technique. X-ray, IR, DC and AC analyses were used to give more information about structural variation that arises due to different doping levels. Semi-crystalline nature of PVA/PVP blend revealed from X-ray diffraction pattern. The crystallinity of the doped blends decays as the doping level of MB increases. The IR analysis showed that a presence of double bond segments which are assumed as an appropriate sites for polarons and/or bipolarons. The dependence of the DC electrical conduction on the temperature was ascribed in view of phonon-assisted interpolaron onedimensional hopping of charge carriers. Dielectric analysis showed that the values of $\varepsilon_{\mathrm{r}}$ decrease with increasing frequency and becomes constant at higher frequencies. On the other hand, $\varepsilon_{\mathrm{r}}$ increases with the temperature. The $\sigma_{\mathrm{ac}}$ values increase with increasing the frequency as well as MB content. The values of the frequency exponent $S$ designate that quantum mechanical tunneling mechanism (QMT) is the dominant model within prepared samples.

Keywords: PVA/PVP blend; XRD; FTIR; electrical conductivity.

\section{$\underline{\text { FULL TEXT }}$}

(C) 2016 The Authors. Published by ESG (www.electrochemsci.org). This article is an open access article distributed under the terms and conditions of the Creative Commons Attribution license (http://creativecommons.org/licenses/by/4.0/). 